\title{
PENELUSURAN KERAGAMAN DALAM BLOK PADA RANCANGAN ACAK KELOMPOK DENGAN INTERGRADIEN
}

\author{
Rita Rahmawati \\ Program Studi Statistika FMIPA UNDIP
}

\begin{abstract}
Abstrak
Dalam Rancangan Acak Kelompok Lengkap (RAKL), asumsi terpenting adalah unit percobaan dalam blok harus bersifat homogen. Asumsi ini sulit dipenuhi jika ukuran blok terlalu besar.

Penelitian ini bertujuan untuk menelusuri keragaman yang ada dalam blok dengan memasukkan unsur arah keragaman (baris atau kolom dalam blok) yang mungkin ada, sehingga analisis ragam yang kemudian dihasilkan akan memberikan keragaman galat yang lebih kecil. Penelusuran keragaman dengan cara ini disebut analisis Intergradien.

Dalam penelitian ini digunakan data jumlah anakan produktif/rumpun yang diperoleh dari Balai Tanaman Padi Sukamandi dalam Penelitian Interaksi antara Genotipe dengan Lingkungan Galur Harapan Padi Sawah pada Agroklimat Utama. Hasil dari penelitian ini, juga dengan data simulasi, memberi kesimpulan bahwa analisis Intergradien dalam RAKL menghasilkan kuadrat tengah galat (KTG) yang lebih kecil daripada RAKL biasa. Tetapi karena unsur baris dan arah keragaman pada data jumlah anakan produktif/rumpun tidak berpengaruh nyata pada alpha 5\%, maka digunakan RAKL biasa untuk menentukan varietas terbaik. Dengan RAKL, didapatkan IR71031 memiliki jumlah anakan produktif/rumpun yang paling besar.
\end{abstract}

Keywords: Rancangan Acak Kelompok Lengkap (RAKL), baris, lajur (kolom), Intergradien, Kuadrat Tengah Galat (KTG)

\section{PENDAHULUAN}

Salah satu rancangan lingkungan yang sering digunakan dalam rancangan percobaan adalah Rancangan Acak Kelompok Lengkap (RAKL). Jenis rancangan ini harus memenuhi asumsi kehomogenan ragam dalam blok. Asumsi ini mudah terpenuhi jika ukuran blok kecil. Namun seringkali penelitian menggunakan banyak unit percobaan sehingga jumlah petak dalam tiap blok relatif banyak dan ukuran tiap blok menjadi besar, yang menyebabkan asumsi kehomogenan ragam sulit dicapai. Tidak menutup kemungkinan juga dalam ukuran blok yang besar ada pengaruh gradien (trend) dalam blok, yang seharusnya bisa ditelusuri sehingga galat yang akhirnya dihasilkan menjadi lebih kecil.

Untuk mengatasi masalah tersebut, salah satu cara yang bisa digunakan adalah analisis Intergradien, yang melibatkan pengaruh baris (kolom) serta trend dalam blok sebagai sumber keragaman. Dalam analisis ini, pereduksian ragam dilakukan dengan memasukkan pengaruh gradien (trend) baris (kolom) dalam model, sehingga dapat diketahui perkiraan arah keragaman yang terjadi dalam baris, kolom atau kombinasi keduanya dalam blok.

\section{TINJAUAN PUSTAKA}

\section{Rancangan Acak Kelompok Lengkap}

RAKL merupakan salah satu rancangan lingkungan yang digunakan untuk mengatasi kesulitan dalam mempersiapkan unit percobaan homogen dalam jumlah besar. Kelompok yang dibentuk harus merupakan kumpulan dari unit-unit percobaan yang relatif homogen 
sedangkan keragaman antar kelompok diharapkan cukup tinggi ${ }^{[4]}$. Asumsi paling penting yang harus dipenuhi dalam RAKL yaitu keragaman dalam kelompok adalah homogen.

Model linier aditif RAKL satu faktor dengan p perlakuan dan r kelompok (blok) adalah:

$$
Y_{i j}=\mu+\tau_{i}+\beta_{j}+\varepsilon_{i j}
$$

dengan :

$\mathrm{i}=1,2,3, \ldots, \mathrm{p} \quad \mathrm{j}=1,2,3, \ldots, \mathrm{r}$

$\mathrm{Y}_{\mathrm{ij}}=$ respon pada perlakuan ke-i, kelompok ke-j

$\mu=$ rataan umum

$\tau_{\mathrm{i}}=$ pengaruh perlakuan ke-i

$\beta_{\mathrm{j}}=$ pengaruh kelompok ke-j

$\varepsilon_{\mathrm{ij}}=$ galat perlakuan ke-i kelompok ke-j.

Struktur tabel analisis ragam dengan RAKL dirumuskan sebagai berikut:

\begin{tabular}{|l|c|c|c|c|}
\hline Sumber & $\mathrm{db}$ & JK & KT & F-hitung \\
\hline Blok & $\mathrm{r}-1$ & JKB & KTB $=$ JKB/( r-1) & KTB/KTG \\
Perlakuan & $\mathrm{p}-1$ & JKP & KTP = JKP/( p-1) & KTP/KTG \\
Galat & (p-1)(r-1) & JKG & KTG = JKG/(p-1)(r-1) & \\
Total & pr - 1 & JKT & & \\
\hline
\end{tabular}

\section{Analisis Intergradien}

Analisis ini dapat diterapkan dengan baik dalam rancangan blok tidak lengkap sebaik rancangan baris-kolom. Model liniernya dapat mengikuti salah satu dari model berikut tergantung pengaruh yang ingin dilihat dalam blok ${ }^{[2]}$ :

$$
\begin{gathered}
Y_{i j k}=\mu+\tau_{i}+\beta_{j}+\rho_{j k}+\pi_{j k} a_{i j k}+\varepsilon_{i j k} \\
Y_{i j k}=\mu+\tau_{i}+\beta_{j}+\rho_{j k}+\pi_{j k} a_{i j k}+\pi_{j} a_{i j k}+\varepsilon_{i j k} \\
\text { atau, } \\
Y_{i j k}=\mu+\tau_{i}+\beta_{j}+\rho_{j k}+\pi_{j k} a_{i j k}+\pi a_{i j k}+\varepsilon_{i j k}
\end{gathered}
$$

dengan :

$\mu$ = rataan umum

$\beta_{\mathrm{j}}=$ pengaruh blok ke-j

$\rho_{\mathrm{jk}}=$ pengaruh baris ke-k dalam blok ke-j

$\mathrm{a}_{\mathrm{ijk}}=$ nilai dari regresi linier terpusat perlakuan ke-i pada posisi dalam blok ke-j baris ke-k

$\pi_{\mathrm{jk}}=$ koefisien regresi linier untuk baris ke-k pada blok ke-j, yang bersifat acak

$\varepsilon_{\mathrm{ijkl}}=$ pengaruh acak (galat)

Dalam tulisan ini digunakan model dengan memasukkan pengaruh intergradien kolom pada tiap blok dengan kontras linier. Untuk data yang digunakan pada penelitian ini, kolom tiap blok adalah 5, sehingga nilai kontras dari kolom 1 sampai 5 berturut-turut adalah -2, -1, 0, 1 dan 2. Analisis Intergradien memperhitungkan arah keragaman dalam blok (Gambar 1).

Dengan rancangan dasar RAKL, struktur tabel analisis ragam Intergradien dirumuskan sebagai berikut:

\begin{tabular}{|l|c|l|c|c|}
\hline Sumber & $\mathrm{db}$ & \multicolumn{1}{|c|}{ JK } & KT & F-hitung \\
\hline Blok & $\mathrm{r}-1$ & JKB & KTP & \\
Perlakuan & $\mathrm{p}-1$ & JKP & KTB & KTB/KTG \\
\hline
\end{tabular}




\begin{tabular}{|l|c|c|c|c|}
\hline Baris (blok) & $\mathrm{r}(\mathrm{u}-1)$ & JKb & KTb & KTb/KTG \\
Klin*baris(blok) & $\mathrm{r}(\mathrm{v}-1)$ & JKkb & KTkb & KTkb/KTG \\
Galat & $g$ & JKG & KTG & \\
Total & $\mathrm{pr}-1$ & JKT & & \\
\hline
\end{tabular}

Ket: $g=\mathrm{r}(\mathrm{p}-\mathrm{u}-\mathrm{v}+1)-(\mathrm{p}-1)$

$\downarrow$\begin{tabular}{|c|c|c|c|c|}
\hline $\mathrm{T}$ & $\mathrm{G}$ & $\mathrm{O}$ & $\mathrm{J}$ & $\mathrm{A}$ \\
\hline $\mathrm{H}$ & $\mathrm{N}$ & $\mathrm{D}$ & $\mathrm{L}$ & $\mathrm{B}$ \\
\hline $\mathrm{E}$ & $\mathrm{Q}$ & $\mathrm{S}$ & $\mathrm{R}$ & $\mathrm{P}$ \\
\hline $\mathrm{C}$ & $\mathrm{M}$ & $\mathrm{F}$ & $\mathrm{I}$ & $\mathrm{K}$ \\
\hline
\end{tabular}

Gambar 1. Ilustrasi penelusuran ragam dalam blok dengan Intergradien

\section{Efisiensi Relatif (ER)}

ER digunakan untuk menentukan besarnya perubahan KTG yang dihasilkan dari dua atau lebih rancangan analisis yang berbeda. Jika KTG yang dihasilkan dengan analisis Interblok lebih kecil dari KTG yang dihasilkan dengan RAKL, artinya analisis Intergradien lebih efisien dan mampu mereduksi keragaman galat lebih besar dari RAKL.

$$
\begin{aligned}
K T G_{R A K L} & >K T G_{R I g} \\
\frac{K T G_{R A K L}-K T G_{R I g}}{K T G_{R A K L}} & >0 \\
E R & >0
\end{aligned}
$$

\section{Uji Kehomogenan Ragam}

Tidak dipenuhinya asumsi kehomogenan ragam galat akan berakibat berkurangnya keefisienan pendugaan beda pengaruh antar perlakuan. Selain itu juga berpengaruh terhadap kepekaan uji-uji nyata. Untuk melihat kehomogenan ragam di sini digunakan uji Bartlett, yang prosedurnya menggunakan pendekatan sebaran khi-kuadrat dengan (p-1) derajat bebas.

Statistik ujinya adalah sebagai berikut :

$$
\begin{aligned}
& \chi^{2}=2.3026\left\{\left(\sum_{i}\left(r_{i}-1\right)\right) \log \left(s^{2}\right)-\sum_{i}\left(r_{i}-1\right) \log \left(s_{i}^{2}\right)\right\} \\
& s_{i}^{2}=\frac{\sum_{j}\left(Y_{i j}-\bar{Y}_{i .}\right)^{2}}{r_{i}-1} ; \quad s^{2}=\frac{\sum\left(n_{i}-1\right) s_{i}^{2}}{N-t}
\end{aligned}
$$

Nilai $\chi^{2}$ dikoreksi sebelum dibandingkan dengan nilai $\chi_{\alpha, \mathrm{p}-1}^{2}$. Nilai $\chi^{2}$ terkoreksi adalah $(1 / \mathrm{FK}) \chi^{2}$, dimana $\quad F K=1+\left[\frac{1}{3(t-1)}\right]\left[\sum_{i} \frac{1}{r_{i}-1}-\frac{1}{\sum r_{i}-1}\right]$

dengan :

$\mathrm{r}$ = banyaknya ulangan

$\mathrm{p}$ = banyaknya perlakuan

Faktor koreksi berfungsi untuk semakin mendekatkan hampiran pada sebaran $\chi^{2}$ bila ukuran contohnya kecil. Faktor koreksi ini selalu lebih besar daripada satu dan 
pengaruhnya menurunkan nilai $\chi^{2}$ yang belum terkoreksi. Sehingga biasanya kita menghitung nilai $\chi^{2}$ terkoreksi nyata tetapi jatuh dekat nilai kritik ${ }^{[4]}$.

Apabila $\chi^{2}<\chi_{\alpha}^{2}$, -1 , maka diterima $\mathrm{H}_{0}$, yang berarti kehomogenan ragam galat percobaan dapat dipenuhi, dan jika sebaliknya, $\mathrm{H}_{0}$ ditolak.

\section{BAHAN DAN METODE}

\section{Sumber Data}

Dalam tulisan ini digunakan data jumlah anakan produktif/rumpun yang diperoleh dari Balai Tanaman Padi Sukamandi dalam Penelitian Interaksi antara Genotipe dengan Lingkungan Galur Harapan Padi Sawah pada Agroklimat Utama di Pusakanagara, yang dianalisis dengan RAKL. Data penelitian ini digunakan sebagai studi kasus untuk memperoleh efek blok dan verietas yang kemudian dicobakan untuk keperluan analisis Intergradien.

Rancangan lingkungan yang digunakan adalah RAKL dengan 4 blok dan 20 varietas padi pada tiap blok.

\begin{tabular}{|c|c|c|c|c|c|c|c|c|}
\hline $\mathrm{E}$ & $\mathrm{J}$ & $\mathrm{I}$ & $\mathrm{P}$ & $\mathrm{CK}$ & $\mathrm{C}$ & $\mathrm{L}$ & $\mathrm{F}$ & $\mathrm{J}$ \\
\hline $\mathrm{S}$ & $\mathrm{T}$ & $\mathrm{R}$ & $\mathrm{B}$ & $\mathrm{AG}$ & $\mathrm{S}$ & $\mathrm{Q}$ & $\mathrm{O}$ & $\mathrm{E}$ \\
\hline $\mathrm{Q}$ & $\mathrm{K}$ & $\mathrm{N}$ & $\mathrm{L}$ & $\mathrm{CN}$ & $\mathrm{B}$ & $\mathrm{P}$ & $\mathrm{M}$ & $\mathrm{I}$ \\
\hline $\mathrm{M}$ & $\mathrm{H}$ & $\mathrm{D}$ & $\mathrm{C}$ & $\mathrm{FA}$ & $\mathrm{D}$ & $\mathrm{H}$ & $\mathrm{T}$ & $\mathrm{R}$ \\
\hline
\end{tabular}

Blok 1

Blok 2

\begin{tabular}{|c|c|c|r||r||r|r|r|r|}
\hline A & T & O & G & R & G & O & J & A \\
\hline L & E & F & H & IH & N & D & L & B \\
\hline B & S & P & N & E & Q & S & R & P \\
\hline M & Q & J & K & C & M & F & I & K \\
\hline
\end{tabular}

Blok 3

Blok 4

Keterangan simbol:

\begin{tabular}{|c|l|}
\hline Simbol & Varietas \\
\hline A & BP17F-MR-99 \\
B & BP342B-MR-30-1 \\
C & BP23F-PN-11 \\
D & BP50F-MR-30-5 \\
E & BP203E-MR-52 \\
F & BP205E-MR-9-1 \\
G & BP226E-MR-76 \\
H & B10177B-MR-2-2-1 \\
I & BP10278B-MR-2-4-2 \\
J & B10299B-MR-116-2-4-1-3 \\
\hline
\end{tabular}

\begin{tabular}{|c|l|}
\hline Simbol & Varietas \\
\hline K & B10299B-MR-116-2-3-5-1 \\
L & S3423E-KN-4 \\
M & S3393-2F-17-1-1 \\
N & S4420F-25-2 \\
O & S4424F-1-1 \\
P & S4325F-1-2-3-1 \\
Q & IR65633-253-3-3-3-2-2 \\
R & IR71031 \\
S & Widas \\
T & Memberamo \\
\hline
\end{tabular}




\section{Metode}

Langkah-langkah analisis yang dilakukan adalah sebagai berikut :

- Pengujian asumsi data hasil penelitian yang dilakukan pada masing-masing data pengamatan.

- Melakukan analisis ragam dengan RAKL.

- Analisis ragam dengan informasi Intergradien, dengan kontras linier terhadap kolom.

- Membandingkan hasil analisis RAKL dan Intergradien, serta menentukan analisis terbaik untuk data yang digunakan dengan melihat nilai kuadrat tengah galat (KTG) yang terkecil dan kesignifikanan unsur-unsur dalam model.

- Menentukan varietas terbaik untuk data penelitian yang digunakan.

\section{HASIL DAN PEMBAHASAN}

\section{Analisis Ragam Data Penelitian}

Hasil analisis ragam untuk jumlah anakan produktif/rumpun dari data penelitian dapat dilihat pada Tabel 1 untuk RAKL dan Tabel 2 untuk Intergradien. Dari ANOVA yang dihasilkan, terlihat bahwa baris dan kolom yang tersarang dalam blok untuk data penelitian ini tidak berpengaruh signifikan terhadap respon. Namun Intergradien menghasilkan nilai KTG 12,42\% dan 19,98\% lebih kecil (ER) dari nilai KTG dengan RAKL biasa. Ini menunjukkan adanya pereduksian keragaman oleh masuknya unsur baris dan kolom.

Tabel 1. Analisis ragam jumlah anakan produktif/rumpun dengan RAKL

\begin{tabular}{|l|c|r|r|l|}
\hline Sumber & Db & \multicolumn{1}{|c|}{ JK } & \multicolumn{1}{|c|}{ KT } & \multicolumn{1}{|c|}{ F-hit } \\
\hline Blok & 3 & 63,586 & 21,195 & $4,54^{* *}$ \\
Varietas & 19 & 762,030 & 40,107 & $8,59^{* *}$ \\
Galat & 57 & 266,014 & 4,667 & \\
Total & 79 & $1,091,630$ & & \\
\hline
\end{tabular}

Keterangan F-hitung : ${ }^{* *}=$ sangat nyata

$$
{ }^{*}=\text { nyata }
$$

Tabel 2. Analisis ragam jumlah anakan produktif/rumpun dengan Intergradien

\begin{tabular}{|l|c|r|r|l|}
\hline Sumber & Db & \multicolumn{1}{|c|}{ JK } & KT & F-hit \\
\hline Blok & 3 & 63,586 & 21,195 & \\
Varietas & 19 & 762,030 & 40,107 & $8,75^{* *}$ \\
Baris (blok) & 12 & 57,728 & 4,811 & 1,05 \\
klin*baris(blok) & 16 & 74,937 & 4,684 & 1,02 \\
Error & 29 & 133,349 & 4,598 & \\
Total & 79 & 1091,630 & & \\
\hline
\end{tabular}

Keterangan F-hitung : ${ }^{* *}=$ sangat nyata

$$
{ }^{*}=\text { nyata }
$$

\section{Varietas Terbaik}

Berdasarkan peubah respon yang diukur, varietas padi yang baik mempunyai jumlah anakan produktif/rumpun besar. Hasil pembandingan nilai rataan setiap varietas dengan rataan terkoreksi berdasar analisis RAKL, varietas dengan jumlah anakan 
produktif/rumpun terbesar adalah varietas IR71031 (R) dan padi dengan jumlah anakan produktif/rumpun terkecil adalah varietas BP342B-MR-30-1 (B).

\section{KESIMPULAN}

Dalam rancangan percobaan dengan unit percobaan yang besar, perlu dilakukan upaya penelusuran keragaman yang mungkin dihasilkan oleh lingkungan sehingga bisa diupayakan pencarian model yang dapat mereduksi dan menelusuri sumber-sumber keragaman yang ada dengan teknik-teknik yang efektif dan efisien.

Dari analisis-analisis yang digunakan pada penelitian ini, model persamaan dengan analisis Intergradien mampu mereduksi keragaman dalam blok lebih besar. Namun karena trend baris (kolom) pada Intergradien untuk data penelitian yang digunakan tidak berpengaruh nyata, penentuan varietas terbaik dilakukan dengan menggunakan RAKL. Dengan analisis RAKL, dari 20 varietas yang dicobakan varietas terbaik adalah varietas IR71031.

Intergradien tidak memberikan pengaruh nyata jika unit percobaan dalam blok sudah relatif homogen, atau cukup heterogen tetapi tidak ada arah keragaman (trend) dalam baris (kolom) di dalam bloknya.

\section{DAFTAR PUSTAKA}

1. Aunuddin. 1989. Analisis Data. Institut Pertanian Bogor. Bogor.

2. Federer, W.T. 1998. Recovery of Interblock, Intergradient, and Intervariety Information in Incomplete Block and Lattice Rectangle Designed Experiments. Biometrics vol 54, halaman 471-481.

3. Gomez, K.A. \& A.A. Gomes. 1984. Statistical Procedures for Agricultural Research. Second Edition. John Wiley \& Sons, Inc. New York.

4. Mattjik, A.A \& Made, Sumertajaya. 2000. Perancangan Percobaan dengan Aplikasi SAS dan Minitab Jilid I. IPB PRESS, Bogor.

5. Steel, R.G.D \& Torrie, J.H. 1995. Prinsip dan Prosedur Statistika. Edisi ke-4. Terjemahan Bambang Sumantri. PT Gramedia Pustaka Utama, Jakarta. 